\title{
Preface: Innovative monitoring techniques and modelling approaches for analysing hydrological processes in small basins
}

\author{
Britta Schmalz ${ }^{1}$, Stephan Dietrich ${ }^{2}$, and João L. M. P. de Lima ${ }^{3}$ \\ ${ }^{1}$ Chair of Engineering Hydrology and Water Management, TU Darmstadt, Darmstadt, Germany \\ ${ }^{2}$ International Centre for Water Resources and Global Change, UNESCO Cat 2 Centre, \\ Federal Institute of Hydrology, Koblenz, Germany \\ ${ }^{3}$ MARE - Marine and Environmental Sciences Centre, Department of Civil Engineering, Faculty of Sciences and Technology \\ of the University de Coimbra, Coimbra, Portugal
}

Correspondence: Britta Schmalz (schmalz@ihwb.tu-darmstadt.de)

Received: 5 July 2019 - Published: 22 July 2019

\section{Motivation}

This Special Issue was produced as a follow-up to the 17th Biennial Conference ERB 2018 and contains contributions summarising conference presentations. The ERB 2018 international conference (https://erb-network.simdif. com/erb-conferences.html, last access: 5 July 2019) was held in Darmstadt, Germany, from 11 to 14 September 2018 and was attended by scientists from 19 different countries. ERB is the Euromediterranean Network of Experimental and Representative Basins (https://erb-network.simdif.com/ index.html, last access: 5 July 2019). It is an open association of 22 European countries operating and managing well instrumented experimental and representative basins for hydrological and environmental research on a long-term basis. The exchange of hydrological information, data and research methods deepens the relationships between the ERB members. Thereby, regular meetings, visits and biennial conferences are organised to bring together research teams, research institutes and universities as well as basin managers from many fields, inter alia hydrology, agricultural and forest sciences. Since 1986 scientific topics of common interest were discussed during biennial ERB conferences.

Additionally, the ERB network promotes the cooperation in international programmes likewise the UNESCO IHP initiatives FRIEND-water (Flow Regimes from International Experimental and Network Data) and Ecohydrology Programme or the Hydrology and Water Resources Programme (HWRP) of the WMO.

The topic of the ERB 2018 international conference was "Innovative monitoring techniques and modelling ap- proaches for analysing hydrological processes in small basins". Hydrological processes can be well studied in small research basins, where high-quality data are available. They serve as interdisciplinary observatories or outdoor laboratories covering the complexity of combined physical, chemical and biological processes in the fields of hydrology and ecohydrology. Furthermore, long-term measurements in small research basins help to analyse environmental changes. New measurement and sensing techniques support further hydrological understanding. For the depiction and understanding of hydrological processes, modelling approaches can be used. On the one hand, hydrological models need sufficient data with high spatial and temporal resolution for model setup, calibration and validation. On the other hand, they offer the possibility to predict processes that are not easily measurable, and allow for the calculation of the impact of supposed scenarios that possibly affect the water cycle and mass transport in the future. Small research basins provide the high-quality data required for model development and testing, also for new and innovative model approaches. Knowledge gained from the complementary use of monitoring and modelling studies in small hydrological basins can be used for decision-making with respect to managing water resources systems.

The sessions of the ERB 2018 conference covered the following topics of small basin research:

- New monitoring and sampling techniques for analysing hydrological processes and biogeochemical fluxes;

- Assessment of water balance components; 
- Measuring erosion and associated transport processes;

- New modelling approaches for analysing (eco-)hydrological and mass transport processes;

- Characterising extreme natural events based on innovative approaches;

- Open session in hydrological research.

\section{Contribution to this special issue}

This special issue does not cover all aspects addressed on the ERB 2018 conference as the topic includes a diversity of issues. Rather it focuses on specific aspects. Four papers were accepted and are published in this volume. The topics reported in this volume cover studies in small hydrological basins considering the heterogeneity of the respective landscape characteristics and agricultural practices. All analyses demonstrate the explicit need for long-term monitoring with high spatial and temporal resolution for process analyses and further strategy planning. A summary of each paper is given in the following.

Bauwe et al. (2019) used the ecohydrological model SWAT (Soil and Water Assessment Tool) to predict streamflow, nitrate loadings and crop yields in a small German agricultural basin (167 ha). Daily streamflow and nitrate data, annual crop yield values and detailed field maps helped to implement exact crop rotations and nitrogen fertilization into the model. From the results of a scenario analysis it was concluded that a slight decrease of nitrogen fertilization leads to significant reductions in nitrate loadings, whereas crop yields remained on a high level. The study outcomes could be used for an economically and ecologically optimal nitrogen management.

Fiener et al. (2019) presented the methodological requirements in measuring soil erosion and runoff from small experimental basins. Therefore, they used a dataset of eight years of monitoring in 14 adjacent small basins ( 0.8 to 13.7 ha) under soil conservation at Scheyern in Germany. As surface runoff and sediment delivery is controlled by highly dynamic spatial and temporal field conditions, their analyses show that rare extreme events led to the major amount of sediment delivery. They highlight that a quantification of these relationships is only possible by sufficiently long monitoring time series.

Application of crop residues (mulch) over the soil surface is a common practice to control soil erosion and promote infiltration. The paper of de Lima et al. (2019) aimed at investigating the effect of different rice straw mulch sizes on runoff and sediment transport. The results of this laboratory study are a contribution to the better understanding of the soil loss process in small areas/basins and to the definition of relevant soil conservation measures, at the plot/field scale.

Montenegro et al. (2019) presented an assessment of near surface soil moisture spatial-temporal distribution and of the impact of soil conservation techniques in reducing runoff and soil loss, using small-scale experimental plots in a representative small basin located in Alto Ipanema River Basin of the Pernambuco State, Brazil. Soil and water monitoring was performed in plots with different soil cover conditions (bare soil plots; plots with natural cover - Caatinga biome vegetation; plots with cactus palma barriers; and plots with dry grass mulch cover), where soil moisture probes were installed. Caatinga was highly effective in terms of soil and water conservation at the small basin scale for both the dry and the wet season, resulting in a positive nexus between vegetation and water availability. The cactus barriers and grass mulching were both effective for soil moisture conservation and for runoff reduction.

\section{Conclusions}

Hydrological studies in small representative basins are essential for investigating the role of distinct water cycle components on water resources conservation and to assess the impact of the natural ecosystems on improving water security. The importance of small research basins will increase in the future, whenever high-quality data is mandatory and processed-based research is needed.

This special issue covers innovative monitoring techniques and modelling approaches for analysing hydrological processes in small areas (experimental plots and laboratory soil flumes) and small hydrological and representative basins. The selected articles comprise analyses on streamflow and nutrient loadings as well as on soil moisture, surface runoff, soil erosion and sediment delivery. They provide four examples on particular scales, appropriate for studying hydrological processes from measurements to data analyses and modelling, in order to determine influencing factors, sources and entry pathways. From this 17th Biennial Conference ERB 2018 - Euromediterranean Network of Experimental and Representative Basins, best practices can be derived, which should be implemented in future sustainable land and water management.

Special issue statement. This article is part of the special issue "Innovative monitoring techniques and modelling approaches for analysing hydrological processes in small basins". It is a result of the 17th Biennial Conference ERB 2018, Darmstadt, Germany, 1114 September 2018.

Acknowledgements. First acknowledgement goes to the authors and participants of the 17th Biennial Conference ERB 2018. The editors would also like to thank all reviewers who contributed to improve the manuscripts submitted to the special issue (which were reviewed by at least two independent reviewers). Also, the editors thank the Copernicus Publishing staff for handling manuscripts during peer-review process. 


\section{References}

Bauwe, A., Kahle, P., and Lennartz, B.: Evaluating the SWAT model to predict streamflow, nitrate loadings and crop yields in a small agricultural catchment, Adv. Geosci., 48, 1-9, https://doi.org/10.5194/adgeo-48-1-2019, 2019.

de Lima, J. L. M. P., Santos, L., Mujtaba, B., and de Lima, M. I. P.: Laboratory assessment of the influence of rice straw mulch size on soil loss, Adv. Geosci., 48, 11-18, https://doi.org/10.5194/adgeo-48-11-2019, 2019.

Fiener, P., Wilken, F., and Auerswald, K.: Filling the gap between plot and landscape scale - eight years of soil erosion monitoring in 14 adjacent watersheds under soil conservation at Scheyern, Southern Germany, Adv. Geosci., 48, 31-48, https://doi.org/10.5194/adgeo-48-31-2019, 2019.
Montenegro, A. A. A., Lopes, I., de Carvalho, A. A., de Lima, J. L. M. P., de Souza, T. E. M. S., Araújo, H. L., Lins, F. A. C., Almeida, T. A. B., and Montenegro, H. G. L. A.: Spatio Temporal Soil Moisture Dynamics and Runoff under Different Soil Cover Conditions in a Semiarid Representative Basin in Brazil, Adv. Geosci., 48, 19-30, https://doi.org/10.5194/adgeo-48-192019, 2019. 